\title{
Determinants of health workers intention to use malaria rapid diagnostic test in Kintampo North Municipality, Ghana - a cross-sectional study
}

Michael Kurubire Anaba ${ }^{1,2^{*}}$ (D) Latifat Ibisomi ${ }^{1,3}$, Seth Owusu-Agyei ${ }^{4,5}$, Tobias Chirwa ${ }^{1}$ and Rohit Ramaswamy ${ }^{6}$

\begin{abstract}
Background: Resistance to antimalarial drugs resulting from overuse of the medication remains a threat to malaria control and elimination in endemic settings including Ghana. Reliance on clinical signs alone results in patients being diagnosed with malaria falsely. The World Health Organization and local guidelines recommend test-based diagnosis with malaria rapid diagnostic test (mRDT) or microscopy before prescription of antimalarial drugs. Despite the scale-up of mRDT through the procurement of mRDT kits and training of health workers on mRDT-led diagnosis of malaria, its use remains low with about $85 \%$ health workers reporting satisfaction with the presumptive diagnosis.
\end{abstract}

Methods: A quantitative cross-sectional study was conducted to investigate the determinants of intention to use mRDT among health workers in Kintampo North Municipality, Ghana. A total of 110 health workers were surveyed from February to April 2017. Intention to use mRDT was measured as the primary outcome with a 5-item scale questionnaire based on the Technology Acceptance Model (TAM). We then tested its association with hypothesized determinants: coherence, cognitive participation, collective action, and reflexive action informed by the Normalization Process Theory (NPT) as well as health workers' background characteristics using linear regression modeling.

Results: The mean intention to use mRDT score was 82\% (SD: 12.6). The regression model showed health workers intention to use mRDT was positively associated with coherence $(\beta=0.40,95 \% \mathrm{Cl} 0.16-0.65)$ and cognitive participation ( $\beta=0.36,95 \% \mathrm{Cl} 0.15-0.58$ ). Intention to use mRDT score was 6.85 units higher among health workers with three or more years of experience compared to those with less than 3 years of experience $(\beta=6.8595 \% \mathrm{Cl}$ 0.59-13.12). However, intention to use mRDT score was inversely related to reflexive monitoring and collective action but not significant.

Conclusion: The study identified that intention to use mRDT was positively influenced by health workers having a proper understanding of the aims and expected benefits (coherence) of the intervention and the availability of experienced staff and intervention champions (cognitive participation) to promote mRDT use among health workers.

Keywords: Intention to use, Rapid diagnostic test, Malaria, Kintampo North Municipality, Ghana

\footnotetext{
* Correspondence: mikeanaba@gmail.com

${ }^{1}$ School of Public Health, Faculty of Health Sciences, University of the

Witwatersrand, Johannesburg, South Africa

${ }^{2}$ Presbyterian Health Service, Agogo, Ghana

Full list of author information is available at the end of the article
}

(c) The Author(s). 2019 Open Access This article is distributed under the terms of the Creative Commons Attribution 4.0 International License (http://creativecommons.org/licenses/by/4.0/), which permits unrestricted use, distribution, and reproduction in any medium, provided you give appropriate credit to the original author(s) and the source, provide a link to the Creative Commons license, and indicate if changes were made. The Creative Commons Public Domain Dedication waiver (http://creativecommons.org/publicdomain/zero/1.0/) applies to the data made available in this article, unless otherwise stated. 


\section{Background}

Forty percent of the global population is at risk of malaria and the majority of this percentage resides in developing countries [1]. According to the World Health Organization (WHO), there were 212 million new cases of malaria in 2016 and Africa accounted for $90 \%$ of the recorded cases [2]. In Ghana, 2.3 million suspected cases of the disease were recorded at Out-Patient Departments (OPD) in the first quarter of 2017, which represent a 1.5\% increase over cases reported during the same period in 2016 [3]. Early, accurate diagnosis with malaria rapid diagnostic test (mRDT) or microscopy and treatment with a recommended antimalarial drug is a key component of malaria control efforts [4]. However, resistance to antimalarial drugs resulting from overuse of the medication remains a threat to malaria control and elimination in endemic settings such as Ghana [5]. Reliance on clinical signs alone results in 32 to $93 \%$ (depending on the local malaria endemicity) of patients being diagnosed with malaria falsely and prescribed antimalarials [6-8]. The WHO recommends a test-based management strategy to ensure appropriate prescription of antimalarial drugs [4].

Ghana rolled out the test-based policy with mRDT-led diagnosis especially in rural facilities where microscopes are often unavailable in 2009 [9]. The national malaria control goal is to provide a correct diagnosis to all suspected malaria cases per treatment guidelines by 2020 [10]. To achieve this objective, there has been scale-up of mRDT through the procurement of mRDT kits and training of health workers on mRDT-led diagnosis of malaria [10]. Despite these efforts, mRDT use is still low [10]. Several studies have explored the sub-optimal implementation of mRDT both in Ghana [11, 12] and in other low and middle-income countries (LMICs) [13]. These studies have all examined health system factors affecting mRDT uptake. In the Rauf et al. study, 96\% of Ghanaian health practitioners stated they knew about mRDT and expressed willingness to implement, yet $85 \%$ were satisfied with presumptive diagnosis [12]. Therefore, it is important to go beyond system factors and begin to consider agent factors. This is also reinforced by the multi-country study by Burchett et al. [13], which states that interventions to improve mRDT implementation were more successful when mRDT fit health practitioners priorities and therefore understanding the process by which actors engage with mRDT is a valuable extension to what is already known. This study responded to this gap through an investigation of factors that affects the intent of front-line staff to use mRDT in Kintampo North Municipality, Ghana.

\section{Conceptual framework}

The use of theory facilitates a better understanding of the generalisability and replicability of implementation interventions [14]. Despite this emphasis, it is recognized that there is no well-established method for theory selection or testing theories [14] and as a result, theories, models and frameworks have proliferated [15]. Therefore, theory selection needs to be governed by considerations about the fit of the theory to the research question [14]. To guide the research, a conceptual framework was adapted from two models [16, 17]. The adapted framework is depicted in Fig. 1. As stated above, the objective of this study was to look at actor specific factors, and a mid-range theory seemed most appropriate. Hence, the Normalization Process Theory (NPT) was selected as one of the theoretical frameworks.

NPT is a general-purpose mid-level theory, and the authors indicated that it can be adapted and used flexibly, which made it attractive for use in this study [18]. A recent systematic review [19] of NPT indicated that the theory was used extensively for process evaluation, and so there is a precedence of its use for the kind of research question of interest in this study. Examples are the use of NPT for evaluating provider-initiated testing and counseling in South Africa [20] and the surgical safety checklist [21]. Our model, therefore, assessed the constructs of NPT that were correlated with intention to use mRDT, since so many providers said they were willing but actual implementation was poor. The hypothesized determinants of intention to use were defined as follows: coherence (sensemaking work done to enhance optimal use of mRDT), cognitive action (operational work done in order to successfully implement mRDT), collective action (the relational work done to build and sustain mRDT) and reflexive monitoring (appraisal work done to understand the effects of mRDT) [22]. Many of the technology adaptation models such as the Technology Acceptance Model (TAM) use intention to use as a proximal indicator for information technology use in healthcare [23], so we have used it as well. Studies have reported the effect of background characteristics of health workers on the use of health interventions [17, 24-26]. As such, we extended the NPT model to investigate further context-related predictors such as age, sex, the cadre of health worker and years of experience.

\section{Methods \\ Study area}

The study was conducted in health facilities across KNM municipality, Ghana. The municipality is in the middle belt of Ghana and covers an area of $7162 \mathrm{~km} 2$ with a resident population of approximately 134,970 [27]. The principal occupation in the area is farming followed by trading. The municipality was selected because of its high fever prevalence of $38 \%$ among children under 5 years, which is above the national prevalence of $19 \%$ [28]. Furthermore, malaria is the leading cause of under-five out-patient attendance in all the facilities in the area $[27,29]$. The municipality has 


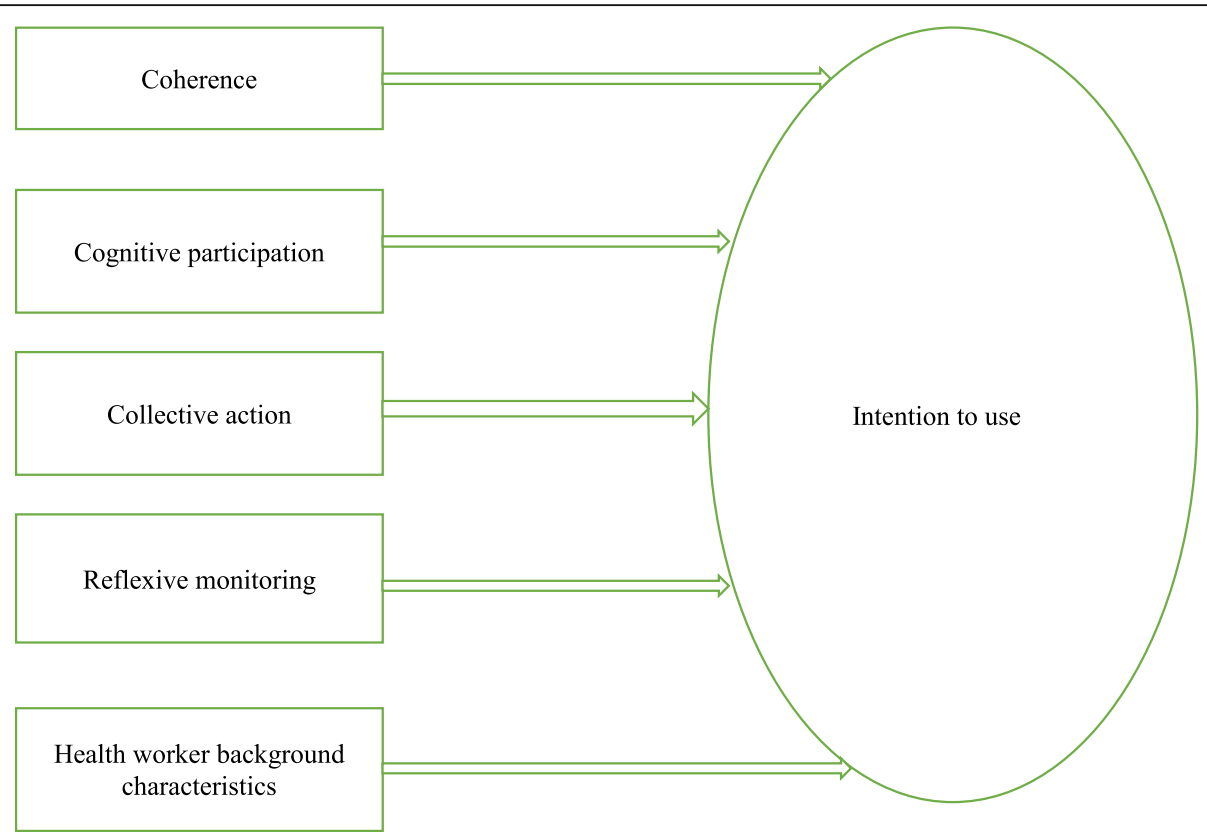

Fig. 1 Conceptual Model on Malaria Rapid Diagnostic Test and its determinants among Health Workers. Adapted from NPT [16] and TAM [17]

one public hospital, four registered private clinics, four health centers and 11 Community-based Health Planning and Services (CHPS) [30].

In the Ghanaian context, hospitals provide clinical care at the district level and serve an average population of 100,000 to 200,000 people [30]. They provide training and technical supervision to health centers at each district or municipality. They offer obstetrics and gynecology, child health, medicine, surgery services and are staffed with more skilled and competent health professional headed by a physician [30]. Health centers and clinics are often headed by a physician assistant and staffed with program heads in the areas of midwifery, laboratory services, public health, environment, and nutrition and serves a population of about 20,000 [30]. They provide basic curative and preventive services for adults and children, as well as reproductive health services and augment their service coverage with outreach services [30]. Basic preventive and curative services for minor ailments are being addressed at the community and household level by CHPS which are staffed by disease control officers, nurses, nurse assistants and community health officers (CHOs) [30].

\section{Study design}

This was a cross-sectional study using a quantitative method.

\section{Study participants}

The study participants included physician assistants, laboratory technologists, nurses and community health officers. These were the cadres of health workers that provide most health care in the primary health facilities in Ghana. Laboratory technologists typically hold a technician diploma or certificate in medical laboratory technology that enables them to collect and assist in processing, analysis and reporting of results of laboratory tests on specimens [30]. Community health officers possess a diploma in disease control or community health and perform follow up investigations of communicable and non-communicable diseases reported to the health facility [30]. Physician assistants hold an advanced diploma or bachelor's degree in community medicine or physician assistantship and provide medical care in rural health facilities that lack physician [30]. Nurses may have a diploma or bachelor's degree and provide nursing care in rural and urban facilities and prescribe medications in facilities that lack physicians or physician assistants [30].

The study was conducted in 19 of the 20 health facilities (one private health facility declined participation) in the municipality. Inclusion as a study participant for the survey required 6 months prior experience in the care of malaria patients. The health facilities provided a list of 125 staff that were directly involved in malaria case management and all were invited to participate in the survey. A total of 110 of the 125 health workers participated in the study.

\section{Data collection}

The survey was in English and carried out from February to April 2017. The survey tool used was a structured interviewer-administered questionnaire. The first part of the questionnaire solicited for health workers' background characteristics of age, sex, education, cadre of health 
workers, years of experience and geographic location. The second part asked questions that assessed the intention to use informed by the TAM. This was structured to elicit Likert scale responses ranging from 1-strongly disagree to 5-strongly agree. This tool has been empirically tested in several studies [31-34]. The third section included the four determinants of intention to use mRDT informed by the NPT NoMAD instrument [35]. These are coherence, collective action, cognitive participation and reflexive monitoring. The 5-point Likert scale was used here too. Four research assistants together with the corresponding author (who was the principal investigator for the study) collected the data.

\section{Quality assurance}

The face validity and content validity of the draft questionnaire were assessed individually by three experts with extensive experience in the field of implementation science and malaria research as well as clinical experience in malaria care in Ghana. They were asked to comment individually on the face validity and content validity of the questionnaire and to judge whether the questions and possible answers were unequivocal. This resulted in minor modifications to the questionnaire. The survey tool was then pilot tested at a health facility in a neighbouring district-Kintampo South Municipality among 35 health workers to establish instrument reliability. Based on the results from this pilot study, the questionnaire was shortened and some questions were rephrased to enhance clarity. In ensuring data quality, research assistants were trained to enhance their understanding of the survey tool. The principal investigator regularly conducted on-site reviews. Data collected were checked for consistency and completeness before data entry.

\section{Data management and analysis}

The collected data were coded, entered into Epi-Info version 7 and exported to STATA/SE Version 14 for analysis. Cronbach's alpha was used to assess the internal consistency of intention to use the construct. The internal consistency of 0.72 for intention to use meant our scale provided a reliable and inter-related measure of the variable [36]. Thus, we computed a composite score for intention to use by summing the Likert scale scores of all the 5 questions that assessed the construct. Composite scores have been noted to increase measurement precision and limit the number of statistical tests needed in analyzing each of the constituent parts separately [35].

NPT to date has primarily been used as a qualitative research tool, but recently, the developers of NPT have created the NoMAD instrument [35]. Since the instrument itself is relatively new, the developers of NoMAD have provided some flexibility for researchers to demonstrate how best it should be used. The general recommendation is that for each item, the percentage of respondents who strongly agreed or agreed should be tallied and the more the positive rating for each construct, the more likely the intervention is likely to be normalized [35]. Summing the scores achieves the same effect since the larger the sum, the greater the positive rating of each construct. The developers of NoMAD and NPT have explicitly stated that this is a pragmatic measure and that they do not have a "formulaic process for scoring or combining items" [35]. Thus, we used an approach that makes the most sense to us given the high Cronbach's alpha value showing high internal consistency of the variables. We computed composite scores by summing up all the item scores for each construct for linear regression analysis. Coherence included 4-items (a score of 4-20), collective action 4-items (a score of 4-20), cognitive participation 7-items (a score of 7-35) and reflexive monitoring 5-items (a score of 525). All the scores were converted to percentages for ease of use and interpretation.

For descriptive analysis, health workers background characteristics was operationalized as follows; sex (1-Female, 2-Male), cadre of health worker (1-Physician assistant, 2-Nurse, 3-Community health officer and 4-laboratory technologist), highest qualification (1-Bachelor's degree, 2Diploma, 3-Senior high certificate), years of experience and geographical location (1-Urban, 2-Rural). We reported these variables using frequencies and percentages while the intention to use, coherence, cognitive participation, collective action, reflexive monitoring and age were summarised with means and standard deviations.

\section{Results}

\section{Study population}

Table 1 summarizes the respondent characteristics. Of the 110 Health Workers, $57.3 \%$ were males. The mean age of respondents was 29.6 (SD: 5.8) years. The majority of the respondents were nurses $(37.3 \%)$ and laboratory technologists were the minority (11.8\%). Health workers with 3 or more years of experience were $52.7 \%$. Those with a bachelor's degree made up $13.6 \%$ of the sample while $63.6 \%$ were high school certificate holders. Two-thirds (66.4\%) of the health workers were based in rural health facilities.

\section{Level of intention to use of mRDT among health workers}

Table 1 also presents the scores of intentions to use mRDT by respondent characteristics. Among the health workers surveyed, the minimum intention to use score was $25 \%$ and the maximum score was $100 \%$ while the mean score was $82 \%$ (SD: 12.6). Health workers with less than 3 years of experience recorded the lower mean intention to use mRDT score (82\%, SD: 12.2) compared to those with three or more years of experience $(87 \%$, SD: 9.9) and this differed significantly. 
Table 1 Descriptive Statistics of the Variables used with Corresponding Mean Score of Intention to Use mRDT

\begin{tabular}{|c|c|c|c|}
\hline Outcome Variable & Score Range (\%) & Mean \% (SD) & \\
\hline Intention to Use & $25-100$ & $82(12.6)$ & \\
\hline \multicolumn{4}{|l|}{ NPT Constructs } \\
\hline Coherence & $45-100$ & $78(12.7)$ & \\
\hline Cognitive participation & $35-100$ & $69(12.8)$ & \\
\hline Collective action & $35-100$ & $69(12.8)$ & \\
\hline Reflexive monitoring & $40-95$ & $72(13.0)$ & \\
\hline Background characteristic & $N=110(\%)$ & Mean Intention to Use \% (SD) & $P$-value \\
\hline Mean Age (SD) & $29.6(5.8)$ & & 0.07 \\
\hline Sex & & & 0.06 \\
\hline Female & $47(42.7)$ & $85(10.8)$ & \\
\hline Male & $63(57.3)$ & $80(13.5)$ & \\
\hline The cadre of Health Workers & & & 0.05 \\
\hline Physician Assistant & $24(21.8)$ & $81(11.6)$ & \\
\hline Nurse & $41(37.3)$ & $85(10.3)$ & \\
\hline Community Health Officer & $32(29.1)$ & $81(11.9)$ & \\
\hline Laboratory Technologist & $13(11.8)$ & $80(16.7)$ & \\
\hline Highest Qualification & & & 0.58 \\
\hline Bachelor's Degree & 15 (13.6) & $85(14.7)$ & \\
\hline Diploma & $25(22.7)$ & $80(11.5)$ & \\
\hline High school Certificate & 70 (63.6) & $82(12.5)$ & \\
\hline Years of Experience & & & $0.01^{*}$ \\
\hline$<3$ years & $52(47.3)$ & $82(12.2)$ & \\
\hline$\geq 3$ years & $58(52.7)$ & $87(9.9)$ & \\
\hline Geographic Location & & & 0.16 \\
\hline Urban & 37 (33.6) & $80(12.3)$ & \\
\hline Rural & 73 (66.4) & $83(12.7)$ & \\
\hline
\end{tabular}

T-test for comparison of values between two groups, ANOVA for comparison of values between more than two groups $S D$ Standard Deviation, $N$ Sample Size

* Statistically significant at $p<0.05$

\section{Multiple linear regression model}

Table 2 presents the coefficients of the (full) model fitted with all the determinants. The intention to use mRDT score increases by 0.40 for every unit increase in health workers' understanding of the relevance and goals of diagnosing malaria with the innovation (coherence). The intention to use mRDT score also increased by 0.36 for every unit increase in health workers willingness to be involved in different aspects of the intervention implementation (cognitive participation). With regards to background characteristics, intention to use mRDT score was 6.85 units higher among health workers with three or more years of experience compared with respondents with less than 3 years of experience.

\section{Discussion}

This study investigated the factors that affect the intention of health workers to use mRDT in the diagnosis of malaria in Kintampo North Municipality, Ghana. The study found an average of $82 \%$ intention to use score among the 110 respondents suggesting that the study population had an overall positive intention to use mRDT. The intention to use mRDT among health workers was influenced by clarity on the benefits and relative advantages (coherence) of mRDT. The finding resonates with the notion that the ability of intervention users to distinguish the relevance of a new intervention is a key determinant of implementation success $[37,38]$. It is worth noting that in the era of presumptive treatment of malaria, case management guidelines required that all children under-five with fever in high-transmission settings including Ghana are prescribed antimalarial drugs [39]. This guideline might still have an impact on prescription behavior despite health workers awareness and willingness to use mRDT. Clearly communicating the goals of mRDT, advantages and how it differs from presumptive diagnosis of malaria is key to 
Table 2 Adjusted Coefficients of Determinants of Intention to Use mRDT

\begin{tabular}{|c|c|}
\hline Determinant & Adjusted Coefficient (95\% Cl) \\
\hline Coherence & $0.40(0.16,0.65) *$ \\
\hline Cognitive Participation & $0.36(0.15,0.58) *$ \\
\hline Collective Action & $-0.20(-0.45,0.04)$ \\
\hline Reflexive Monitoring & $-0.04(-0.25,0.16)$ \\
\hline Age of health worker & $0.43(-3.34,4.21)$ \\
\hline \multicolumn{2}{|l|}{ Experience of health worker } \\
\hline Below 3 years & Ref \\
\hline 3 years and above & $6.85(0.59,13.12) *$ \\
\hline \multicolumn{2}{|l|}{ Sex } \\
\hline Female & Ref \\
\hline Male & $-1.71(-6.34,2.91)$ \\
\hline \multicolumn{2}{|c|}{ The geographical location of health worker } \\
\hline Urban & Ref \\
\hline Rural & $3.44(-2.66,9.55)$ \\
\hline \multicolumn{2}{|l|}{ Highest qualification } \\
\hline Bachelor's degree & Ref \\
\hline Diploma & $1.29(-5.84,8.44)$ \\
\hline High School Certificate & $0.49(-7.84,8.84)$ \\
\hline \multicolumn{2}{|l|}{ Cadre of health worker } \\
\hline Physician assistants & Ref \\
\hline Nurse & $2.99(-6.22,12.20)$ \\
\hline Community health officers & $3.66(-1.67,9.00)$ \\
\hline Laboratory technologists & $1.07(-5.72,7.87)$ \\
\hline
\end{tabular}

enhancing intention to use as a proximal indicator for mRDT use.

The intention to use mRDT among health workers in this study was enhanced by the availability of innovation champions or initiators and readiness for change practices (cognitive participation). This is consistent with a study in South Africa which found that using early intervention adopters or users of intervention as champions to drive implementation forward facilitated successful implementation of provider-initiated testing innovation [40]. The introduction of a new intervention to the clinical setting is often disruptive hence a comprehensive change management strategies involvement of staff, and the early identification of champions who are prepared to promote the initiative are important for optimal implementation [41]. Understanding front-line users' needs and development of strategies to encourage interprofessional collaboration and protocols for new intervention use are crucial strategies for successful implementation of health technology like mRDT [42].
Evidence suggests that health workers are less likely to engage with innovation if they feel that its implementation had not eased their workload [43]. This validates our findings that availability of resources, enough time and staff (collective action) are negative predictors of intention to use mRDT among health workers in this study. There is evidence that suggests that health workers in urban health facilities are unable to fully implement the test-based management of malaria due to heavy clinic work-loads and that mRDT had altered health worker roles $[44,45]$. Also, poor experience with the initial implementation of new interventions was more likely to result in implementation failure [40].

This study also found that having three or more years of experience was positively associated with mRDT compared to having fewer than three-year experience. This may indicate that the intention to use of mRDT comes from experience with mRDT use. These results are consistent with the report that having more years of experience is associated with higher health technology acceptance [46].

\section{Strengths and limitations}

The study was conducted in only health facilities in KNM and this limits the generalizability of the finding beyond the study area. This was solely a quantitative study, and therefore qualitative approach may enhance a deeper understanding of context-specific factors that might influence intention to use mRDT. Lastly, this study was based on the intention to use as a proximal indicator of use, therefore we suggest future research should explore actual use of the innovation.

\section{Theoretical and practical implications}

Using the NPT and TAM as theoretical guides in this study facilitated a deeper understanding of the process by which actors may engage in mRDT implementation which is critical for future research, practice and policy. This study has practical implications in particular for policymakers and healthcare professionals who strive to normalize mRDTs and similar technologies in developing countries like Ghana. Special attention should be paid to health care professionals who have less experience and those who show less intention of using mRDTs. Providing technical support may get them accustomed to new intervention which may boost acceptance and use [47]. Our study also underscores the importance of early adopter in motivating other health workers as well as showing the potential benefits of mRDTs. It has been found that when nursing staff thought the patient would benefit from new technology, the nursing staff themselves were more willing to actually use it. The opposite was also found when the anticipated benefits for the patient were thought to be low or unclear, thereby impeding the intervention use [47]. So, 
when introducing an evidence-based intervention like $\mathrm{mRDT}$, health professionals must also believe in the benefits of the intervention.

\section{Conclusion}

The study found that intention to use mRDT among health workers are influenced by clarity on the benefits and goals of the intervention and availability of innovation champions or initiators to promote the intervention use among health workers. Change management strategies such as technical support and training of frontline staff are also imperative in boosting the intention to use mRDT.

\section{Abbreviations}

CHPS: Community-Based Health Planning and Services; HREC: Human Research Ethics Committee; IMCI: Integrated Management of Childhood IIIness; KNM: Kintampo North Municipality; MRDT: Malaria Rapid Diagnostic Test; NPT: Normalization Process Theory; TAM: Technology Acceptance Model

\section{Acknowledgments}

We would like to also express our sincere gratitude for the contributions of staff in School of Public Health, Faculty of Health Sciences, University of the Witwatersrand, Johannesburg, South Africa, Gillings School of Public Health, University of North Carolina, Chapel Hill, NC. The authors are grateful to the study participants and health facilities for their participation in this study. We deeply appreciate the dedication and efforts of the research assistants, staff and leadership of Kintampo Health Research Centre. MKA would like to thank Mr. Kenneth Ae-Ngibise, Ms. Lorraine Molepo and Mr. Lawrence Yirkyio for their invaluable feedback and support.

\section{Authors' contributions}

The paper is derived from the MSc Epidemiology (in the field of Implementation Science) research of the first/corresponding author. MKA designed the study with LI, RR and SOA. MKA conducted the literature review, statistical analysis, interpretation of the results and discussion with the manuscript review from the entire team. MKA and LI coordinated the implementation of the study. $\mathrm{LI}$ and RR guided the analysis and writing up of the work; TC provided guidance on methodology and statistical analysis; LI, SOA, RR and TC participated in refining the initial research idea and critically reviewed the drafts. All authors provided critical revisions and approved the final submitted manuscript.

\section{Funding}

This paper presents independent research funded by TDR, the Specia Programme for Research and Training in Tropical Diseases, which is hosted at the World Health Organization and co-sponsored by UNICEF, UNDP, the World Bank and WHO. TDR grant number: B40299. First author ORCID ID: 0000-0002-6767-6406. The funding source played no role in the study design, data collection, analysis or interpretation, or the writing of the manuscript. The researchers retain complete independence in the conduct of the study.

\section{Availability of data and materials}

The datasets used and/or analysed during the current study are available from the corresponding author on reasonable request.

\section{Ethics approval and consent to participate}

Ethical approval was sought from the Wits Human Research Ethics Committee (HREC) and the Institutional Ethics Committee (IEC) of the Kintampo Health Research Centre in Ghana. The Wits HREC (non-Medical) approved this study on 13th January 2017 with clearance certificate no: M161196. The study also received ethical approval from the IEC of Kintampo Health Research Centre in Ghana with certificate no: KHRCIEC 2017-1. Permission was also sought from the Municipal Health Directorate and management of the health facilities included in the study. Anonymity and confidentiality were assured before the interviews were conducted and we obtained written informed consent from all participants.
Consent for publication

Not applicable.

\section{Competing interests}

The authors declare that they have no competing interests.

\section{Author details}

${ }^{1}$ School of Public Health, Faculty of Health Sciences, University of the Witwatersrand, Johannesburg, South Africa. ${ }^{2}$ Presbyterian Health Service, Agogo, Ghana. ${ }^{3}$ Nigerian Institute of Medical Research, Yaba, Nigeria. ${ }^{4}$ Kintampo Health Research Centre, Kintampo, Ghana. ${ }^{5}$ The University of Health and Allied Sciences, Ho, Ghana. ${ }^{6}$ Gillings School of Global Public Health, University of North Carolina, Chapel Hill, USA

Received: 22 January 2019 Accepted: 5 July 2019

Published online: 15 July 2019

\section{References}

1. National Malaria Control Center [Internet]. [cited 2019 Jul 19]. Available from: https://www.nmec.org.zm/malaria-overivew.

2. WHO | Fact Sheet: World Malaria Report 2016 [Internet]. WHO. [cited 2017 Jun 18]. Available from: http://www.who.int/malaria/media/world-malariareport-2016/en/

3. 2017-1st Quarter Bulletin.pdf [Internet]. [cited 2018 Jun 2]. Available from: http://www.ghanahealthservice.org/downloads/2017-1st_Quarter_Bulletin. pdf.

4. $\quad \mathrm{WHO}$ | World malaria report 2018 [Internet]. WHO. [cited 2019 Mar 13]. Available from: http://www.who.int/malaria/publications/world-malariareport-2018/en/.

5. $\mathrm{WHO} \mid$ Responding to antimalarial drug resistance [Internet]. WHO. [cited 2019 Jan 22]. Available from: http://www.who.int/malaria/areas/drug_ resistance/overview/en/.

6. Zikusooka CM, Mclntyre D, Barnes Kl. Should countries implementing an artemisinin-based combination malaria treatment policy also introduce rapid diagnostic tests? Malar J. 2008;7:176.

7. Koram KA, Molyneux ME. When is "malaria" malaria? The different burdens of malaria infection, malaria disease, and malaria-like illnesses. Am J Trop Med Hyg. 2007;77(6 Suppl):1-5.

8. Rolland E, Checchi F, Pinoges L, Balkan S, Guthmann J-P, Guerin PJ. Operational response to malaria epidemics: are rapid diagnostic tests costeffective? Trop Med Int Health TM IH. 2006;11(4):398-408.

9. Resources [Internet]. MalariaCare. 2013 [cited 2017 Jun 18]. Available from: https://malariacare.org/resources/.

10. Ghana Malaria Operational Plan FY 2018.pdf [Internet]. [cited 2019 May 5]. Available from: https://reliefweb.int/sites/reliefweb.int/files/resources/fy-201 8-ghana-malaria-operational-plan.pdf.

11. Boadu NY, Amuasi J, Ansong D, Einsiedel E, Menon D, Yanow SK. Challenges with implementing malaria rapid diagnostic tests at primary care facilities in a Ghanaian district: a qualitative study. Malar J. 2016;15(1): 126 [cited 2017 Jun 4] Available from: https://malariajournal.biomedcentral. com/articles/10.1186/s12936-016-1174-0.

12. Rauf A, Anto BP, Koffuor GA, Buabeng KO, Abdul-Kabir M. Introducing Malaria Rapid Diagnostic Tests (MRDTs) at Registered Retail Pharmacies in Ghana: Practitioners' Perspective. Br J Pharm Res. 2014;4(8):943 [cited 2017 Apr 3] Available from: http://search.proquest.com/openview/dafa389bda783 9a76390f909862834bf/1?pq-origsite=gscholar\&cbl=626441.

13. Burchett HED, Leurent B, Baiden F, Baltzell K, Björkman A, Bruxvoort K, et al. Improving prescribing practices with rapid diagnostic tests (RDTs): synthesis of 10 studies to explore reasons for variation in malaria RDT uptake and adherence. BMJ Open. 2017;7(3):e012973 [cited 2019 May 20]; Available from: https://bmjopen.bmj.com/content/7/3/e012973.

14. The Improved Clinical Effectiveness through Behavioural Research Group (ICEBeRG). Designing theoretically-informed implementation interventions. Implement Sci. 2006;1(1):4 [cited 2019 May 20] Available from: https://doi. org/10.1186/1748-5908-1-4.

15. Nilsen P. Making sense of implementation theories, models and frameworks Implement Sci. 2015;10(1):53 [cited 2019 Jan 5] Available from: https://doi. org/10.1186/s13012-015-0242-0.

16. Finch TL, Rapley T, Girling M, Mair FS, Murray E, Treweek S, et al. Improving the normalization of complex interventions: measure development based on normalization process theory (NoMAD): study protocol. Implement Sci. 
2013:8(1):43 [cited 2019 mar 28] Available from: https://doi.org/10.1186/174 8-5908-8-43.

17. Venkatesh M, Davis D. User Acceptance of Information Technology: Toward a Unified View. MIS Q. 2003;27(3):425 [cited 2018 Jul 31] Available from: https://www.jstor.org/stable/10.2307/30036540.

18. May C. Agency and implementation: Understanding the embedding of healthcare innovations in practice. Soc Sci Med. 2013;78:26-33 [cited 2019 May 20] Available from: http://www.sciencedirect.com/science/article/pii/ S0277953612007708.

19. May CR, Cummings A, Girling M, Bracher M, Mair FS, May CM, et al. Using Normalization Process Theory in feasibility studies and process evaluations of complex healthcare interventions: a systematic review. Implement Sci. 2018;13(1):80 Available from: https://doi.org/10.1186/s13012-018-0758-1.

20. Leon N, Lewin S, Mathews C. Implementing a provider-initiated testing and counselling (PITC) intervention in Cape town, South Africa: a process evaluation using the normalisation process model. Implement Sci. 2013;8(1):97 [cited 2019 May 20] Available from: https://doi.org/10.1186/1748-5908-8-97.

21. Gillespie BM, Harbeck E, Lavin J, Gardiner T, Withers TK, Marshall AP. Using normalisation process theory to evaluate the implementation of a complex intervention to embed the surgical safety checklist. BMC Health Serv Res. 2018 18. [cited 2019 May 20] Available from: https://www.ncbi.n/m.nih.gov/ pmc/articles/PMC5845378/

22. Finch TL, Mair FS, O'Donnell C, Murray E, May CR. From theory to'measurement'in complex interventions: Methodological lessons from the development of an e-health normalisation instrument. BMC Med Res Methodol. 2012;12(1):69 [cited 2017 May 18] Available from: https:// bmcmedresmethodol.biomedcentral.com/articles/10.1186/1471-2288-12-69.

23. Holden RJ, Karsh B-T. The Technology Acceptance Model: Its past and its future in health care. J Biomed Inform. 2010;43(1):159-72 [cited 2019 Mar 16] Available from: http://www.sciencedirect.com/science/article/pii/S1532 046409000963.

24. Kalkan A, Roback K, Hallert E, Carlsson P. Factors influencing rheumatologists' prescription of biological treatment in rheumatoid arthritis: an interview study. Implement Sci IS. 2014;9:153.

25. Seuwou P, Banissi E, Ubakanma G. User Acceptance of Information Technology: A Critical Review of Technology Acceptance Models and the Decision to Invest in Information Security. In: Global Security, Safety and Sustainability - The Security Challenges of the Connected World [Internet]. Springer, Cham; 2017 [cited 2018 Jul 31]. p. 230-51. (Communications in Computer and Information Science). Available from: https://ink.springer. com/chapter/10.1007/978-3-319-51064-4_19

26. Damschroder $L$, Aron DC, Keith RE, Kirsh SR, Alexander JA, Lowery JC. Fostering implementation of health services research findings into practice: a consolidated framework for advancing implementation science. Implement Sci. 2009;4(1):50 Available from: https://doi.org/10.1186/1748-5908-4-50.

27. Owusu-Agyei S, Nettey OEA, Zandoh C, Sulemana A, Adda R, AmengaEtego S, et al. Demographic patterns and trends in Central Ghana: baseline indicators from the Kintampo Health and Demographic Surveillance System. Glob Health Action. 2012;5. [cited 2019 Mar 14] Available from: https://www. ncbi.nlm.nih.gov/pmc/articles/PMC3529298/

28. Ghana_MICS_Final.pdf [Internet]. [cited 2018 Aug 8]. Available from: https:// www.unicef.org/ghana/Ghana_MICS_Final.pdf

29. Ghana Health Service Regional Health Directorate (2005) Performance Review Report. Sunyani: Ghana H - Smart Search [Internet]. [cited 2016 Aug 29]. Available from: http://thesmartsearch.net/search?p=acp8\&q=Ghana\%2 OHealth\%20Service\%20Regional\%20Health\%20Directorate\%20(2005 )\%20Performance\%20Review\%20Report.\%20Sunyani:\%20Ghana\%20H\&si=98

30. GHS_ANNUAL_REPORT_2016_n.pdf [Internet]. [cited 2018 Jun 16]. Available from: http://ghanahealthservice.org/downloads/GHS_ANNUAL_REPORT_2016_n.pdf

31. Goodarzi H, Khatami S-M, Javadzadeh H, Mahmoudi S, Khajehpour H, Heidari S, et al. User Acceptance of Picture Archiving and Communication System in the Emergency Department. Iran J Radiol [Internet]. 2016 Mar 12 [cited 2017 May 19];In Press (In Press). Available from: http://www.Iranjradiol. $\mathrm{com} /$ ?page $=$ article\&article_id $=20102$

32. Duyck P, Pynoo B, Devolder P, Voet T, Adang L, Ovaere D, et al. Monitoring the PACS Implementation Process in a Large University Hospital_Discrepancies Between Radiologists and Physicians. J Digit Imaging. 2010;23(1):73-80. [cited 2017 May 20] Available from: https://link. springer.com/article/10.1007/s10278-008-9163-7

33. Van Schaik P, Bettany-Saltikov JA, Warren JG. Clinical acceptance of a lowcost portable system for postural assessment. Behav Inf Technol. 2002;21(1):
47-57. [cited 2017 May 20] Available from: http://www.tandfonline.com/doi/ abs/10.1080/01449290110107236

34. Naenna T, Phichitchaisopa N. Factors affecting the adoption of healthcare information technology. 2013 [cited 2017 May 19]; Available from: https:// eldorado.tu-dortmund.de/handle/2003/30486

35. Normalization Process Theory | Data collection tools [Internet]. [cited 2019 Mar 30]. Available from: http://normalizationprocess.org/how-do-you-usenpt/survey-research/data-collection-tools/

36. Composite Scoring and Reliability [Internet]. Statistics Solutions. 2017 [cited 2018 Jul 14]. Available from: http://www.statisticssolutions.com/compositescoring-and-reliability/

37. Audrey S, Holliday J, Campbell R. Commitment and compatibility: Teachers' perspectives on the implementation of an effective school-based, peer-led smoking intervention. Health Educ J. 2008;67(2):74-90 Available from: https://doi.org/10.1177/0017896908089387.

38. Waller G, Finch T, Giles EL, Newbury-Birch D. Exploring the factors affecting the implementation of tobacco and substance use interventions within a secondary school setting: a systematic review. Implement Sci. 2017;12(1). [cited 2018 Jul 31] Available from: https://implementationscience. biomedcentral.com/articles/10.1186/s13012-017-0659-8

39. WHO | Integrated Management of Childhood IIIness (IMCI) [Internet]. WHO. [cited 2018 May 20]. Available from: http://www.who.int/maternal_child_ adolescent/topics/child/imci/en/.

40. Mair FS, May C, O'Donnell C, Finch T, Sullivan F, Murray E. Factors that promote or inhibit the implementation of e-health systems: an explanatory systematic review. Bull World Health Organ. 2012;90(5):357-64 [cited 2017 May 13] Available from: http://www.who.int/entity/bulletin/volumes/ 90/5/11-099424.pdf.

41. Patterson V, Bingham E. Telemedicine for Epilepsy: A Useful Contribution. Epilepsia. 2005;46(5):614-5 [cited 2019 Mar 16] Available from: https:// onlinelibrary.wiley.com/doi/abs/10.1111/j.1528-1167.2005.05605.x.

42. Jennett $P$, Yeo M, Pauls M, Graham J. Organizational readiness for telemedicine: Implications for success and failure. J Telemed Telecare. 2003; 9(2_suppl):27-30. [cited 2019 Mar 16] Available from: https://doi.org/10.125 8/135763303322596183.

43. Odeh B, Kayyali R, Nabhani-Gebara S, Philip N. Implementing a telehealth service: nurses' perceptions and experiences. Br J Nurs. 2014;23(21):1133-7 [cited 2019 Mar 16] Available from: https://www.magonlinelibrary.com/doi/ abs/10.12968/bjon.2014.23.21.1133.

44. Asiimwe C, Kyabayinze DJ, Kyalisiima Z, Nabakooza J, Bajabaite M, Counihan $\mathrm{H}$, et al. Early experiences on the feasibility, acceptability, and use of malaria rapid diagnostic tests at peripheral health centres in Uganda-insights into some barriers and facilitators. Implement Sci. 2012;7(1):5 [cited 2017 Jun 4]. Available from: https://implementationscience.biomedcentral.com/articles/1 0.1186/1748-5908-7-5.

45. Febir LG, Baiden FE, Agula J, Delimini RK, Akpalu B, Tivura M, et al. Implementation of the integrated management of childhood illness with parasitological diagnosis of malaria in rural Ghana: health worker perceptions. Malar J. 2015;14:174. [cited 2017 Jul 4] Available from: https:// doi.org/10.1186/s12936-015-0699-y.

46. Norman CD, Skinner HA. eHEALS: The eHealth Literacy Scale. J Med Internet Res. 2006 ;8(4). [cited 2017 May 19] Available from: http://www.ncbi.nlm.nih. gov/pmc/articles/PMC1794004/.

47. de Veer AJ, Fleuren MA, Bekkema N, Francke AL. Successful implementation of new technologies in nursing care: a questionnaire survey of nurse-users. BMC Med Inform Decis Mak. 2011;11:67 [cited 2019 May 21]; Available from: https://www.ncbi.nlm.nih.gov/pmc/articles/PMC3214145/.

\section{Publisher's Note}

Springer Nature remains neutral with regard to jurisdictional claims in published maps and institutional affiliations. 